\title{
Optimal Speed Control Humps Design Based on Driver Comfort
}

\author{
H. Gheibollahi* and M. Masih-Tehrani
}

Vehicle Dynamical System Research Lab, School of Automotive Engineering, Iran University of Science and Technology, Tehran, Iran * POB 16846-13114 Tehran, Iran

\begin{abstract}
The purpose of this study is to optimise the different speed control humps by considering the vertical and horizontal acceleration of the driver's head. In previous researches, the main focus was only on vertical acceleration, but in this study, horizontal acceleration of the head is also considered. Here, the root mean square (RMS) of acceleration of head is considered as a measure of occupant comfort. The modelling is performed by a non-linear half-car suspension system (4-DOF) with a linear model of a driver (10-DOF) and a seat. The hamps under study are circular, sinusoidal, half-sinusoidal, and trapezoidal. Finally, by analysing the results, the optimal design of each type of hump is performed. The objective function used is a combination of horizontal and vertical acceleration which is performed using MATLAB genetic algorithm. The results show a significant reduction in horizontal and vertical acceleration at all speeds. From this modelling, it is possible to extract a suitable range for passing the speed of cars over different types of humps. In this study, it is shown that the acceleration values for the circular and half-sinusoidal humps at all speeds are quite close to each other.
\end{abstract}

ARTICLE HISTORY

Received: $11^{\text {th }}$ Jan 2021

Revised: $27^{\text {th }}$ July 2021

Accepted: $26^{\text {th }}$ Aug 2021

\section{KEYWORDS}

Biodynamic model;

Driver comfort;

Genetic algorithm;

Speed control humps

(SCHs);

Vehicle suspension

\section{NOMENCLATURE}

\begin{tabular}{|c|c|c|c|}
\hline$m_{b}$ & vehicle body mass & $k_{r 2}$ & rear suspension spring stiffness \\
\hline$m_{f}$ & front unsprung mass & $c_{f 1}$ & front tire damping \\
\hline$m_{r}$ & rear unsprung mass & $c_{r 1}$ & rear tire damping \\
\hline$I_{b}$ & vehicle body inertia & $c_{f 2 u}$ & front suspension spring damping for tension \\
\hline$l_{f}$ & front length & $c_{f 2 d}$ & front suspension spring damping for compression \\
\hline$l_{r}$ & rear length & $c_{r 2 u}$ & rear suspension spring damping for tension \\
\hline$l_{1}$ & $\mathrm{CG}$ to pelvis length & $c_{r 2 d}$ & rear suspension spring damping for tension \\
\hline$l_{2}$ & CG to backrest length & $x_{b}(t)$ & Displacement of $\mathrm{m}_{\mathrm{b}}$ \\
\hline$g$ & Gravitational acceleration & $\theta$ & Angular displacement of $\mathrm{m}_{\mathrm{b}}$ \\
\hline$k_{f 1}$ & front tire stiffness & $x_{f}(t)$ & displacement of $\mathrm{m}_{\mathrm{f}}$ \\
\hline$k_{r 1}$ & rear tire stiffness & $x_{r}(t)$ & displacement of $\mathrm{m}_{\mathrm{r}}$ \\
\hline$k_{f 2}$ & front suspension spring stiffness & $x_{f d}(t)$ & excitation to the front tire \\
\hline$L$ & hump length & $x_{r d}(t)$ & excitation to the rear tire \\
\hline$h(t)$ & hump height & $v$ & speed of car \\
\hline$H$ & maximum height of hump & $R$ & radius of circular profile \\
\hline$m_{1}$ & mass of upper leg (left + right $)$ & $m_{5}$ & mass of head and neck \\
\hline$m_{2}$ & mass of pelvic & $m_{s}$ & mass of seat \\
\hline$m_{3}$ & $\begin{array}{l}\text { mass of viscera (soft abdominal body } \\
\text { parts) }\end{array}$ & $I_{h}$ & head inertia \\
\hline$m_{4}$ & mass of upper torso (including hands) & $l_{h}$ & distance from headrest to the neck joint \\
\hline$k_{1 v}, k_{1 h}$ & $\begin{array}{l}\text { upper leg vertical and horizontal } \\
\text { springs }\end{array}$ & $c_{1 v}, c_{1 h}$ & upper leg vertical and horizontal dampers \\
\hline$k_{2 v}, k_{2 h}$ & pelvic vertical and horizontal springs & $c_{2 v}, c_{2 h}$ & pelvic vertical and horizontal dampers \\
\hline$k_{4 v}, k_{4 h}$ & back horizontal and vertical springs & $c_{4 v}, c_{4 h}$ & back horizontal and vertical dampers \\
\hline$k_{5 v}, k_{5 h}$ & head horizontal and vertical springs & $c_{5 v}, c_{5 h}$ & head horizontal and vertical dampers \\
\hline$k_{21} \sim k_{54}$ & $\begin{array}{l}\text { the respective springs between body } \\
\text { segments }\end{array}$ & $c_{21} \sim c_{54}$ & the respective dampers between body segments \\
\hline$k_{r}$ & neck rotation stiffness & $c_{r}$ & Neck rotation damping \\
\hline
\end{tabular}

\section{INTRODUCTION}

Today, passenger and driver comfort is one of the most important issues in the field of car design. When the car is moving on a track, the shape of the track profile causes continuous vibrations and hits the car and the driver. Some of these vibrations are absorbed by the tires, but the main task to eliminate the effects of vibration is the car's suspension. 
The suspension is a mechanism that sits between the tires and the body and has a significant effect on providing occupant comfort. However, the type of road can affect any suspension. Also, proper seat design is another parameter that affects occupant comfort [1],[2]. One of the things that excites the suspension is the hump. The common name for them is speed control hump (SCH). Speed control humps (SCHs) are profiles that are created on the road surface to improve safety conditions by creating speed limits [3]. Today, the use of SCHs is widespread around the world, and low-speed limits, below $40 \mathrm{~km} / \mathrm{h}(25 \mathrm{mph})$ or lower, are usually applied. Although speed humps slow down cars in some parts of the road, in some cases using them can be problematic. Poorly designed humps can injure drivers and vehicles even at low speeds. Humps slow down emergency vehicles. Many sports cars have problems with such humps. Also, it can increase traffic noise. As well as if the bumps do not have warning signs and cannot be seen, they can pose a serious hazard to cyclists and motorcyclists [4]. Design standards and their creation are different in different countries.

In general, there are three types of shapes for them, which are circular [5], sinusoidal [6],[7], and trapezoidal [8]. Mathematical modelling of car suspension can be done in different ways. Full-car, half-car, and quarter-car models are the most basic modelling. The simplest model is a quarter-car suspension model with 2-DOF in which the spring and damper are placed between the body and the tire. The tire is in contact with the ground by a spring [9]. The half-car model is a two-wheel model with 4-DOF. This model is suitable for studying the vertical and pitch motions [8]. Also, it is simpler than the full-car model, and unlike the quarter model, it allows the study of the pitch and vertical motions. Also, it is possible to study the deflection of tires and suspensions in this model. A full-car model is a model with 7-DOF. This is a complex model and is used for studying the pitch, roll, and vertical motions [3]. In each of these cases, the springs can be considered linear or non-linear. In cases where the movement path is perfectly smooth, and the displacement of springs and dampers is small, the model can be considered linear, but in cases where the path is uneven, non-linear modelling is closer to the real state of the suspension. In the non-linear state, the effects of turbulence can also be observed in some specific stimulation because chaos is one of the most important issues in the suspension system that can cause damage to the car and the driver. To study the vibrations on the driver, the body and seat can be modelled in three ways. One method is the lumped parameter in which the body is divided into moments without a moment of inertia, and springs and dampers are placed between them [10]. Another method is to use a multi-body model in which different parts of the body have inertial moments, and it is possible to rotate them[11]. The third method is to use the finite element method, which is used to study the stresses and forces on any part of the body [12]. In research on body vibrations, one of these three types of models is used according to the intended purpose.

In this research, non-linear modelling of the suspension system has been performed using a half-car model [8]. Then the modelling of the driver body has been done with a change in the Harsha model [13]. Harsha model [14] is a model with nine degrees of freedom, which by adding a pitch motion to the head and converting the model to ten degrees of freedom, it is possible to study the horizontal vibrations of the head. The input excitations of the models are circular, trapezoidal, sinusoidal humps. Equations of motion for hump, suspension, and body are solved using MATLAB software. The vibration output of the non-linear suspension is used as the input of the linear model of the body. By solving the equations, horizontal and vertical head accelerations values are obtained for different types of bumps at different speeds. Finally, using the genetic algorithm and defining the objective function based on horizontal and vertical head accelerations, the optimal length for different types of humps is obtained.

\section{METHODOLOGY AND MODELLING}

\section{Hump Excitation Modelling}

In this section, we intend to model the different hump profiles using mathematical functions. In this study, sinusoidal, half-sinusoidal, circular, and trapezoidal humps were modelled. Since the height of the humps is not a parameter studied in this article, its value is considered equal to $10 \mathrm{~cm}$. According to the standards, the length of the bump is considered between 3 and $4.5 \mathrm{~m}$. [4].

\section{Half-sinusoidal hump modelling}

First, we model the half-sinusoidal hump. Figure 1 shows the diagram of the half-sine. In this diagram, only half of the periodicity of the sine function has a value, and the other points have a value of zero. The function of this hump is given in Eq. (1) [6],[7].

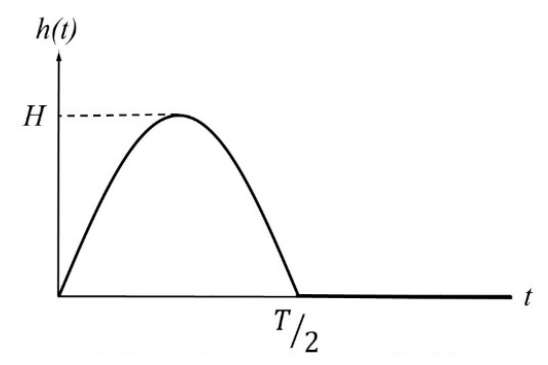

Figure 1. Geometric shape for the half-sinusoidal hump. 


$$
h(t)= \begin{cases}H \sin \left(\frac{2 \pi t}{T}\right) & t \leq \frac{T}{2} \\ 0 & t>\frac{T}{2}\end{cases}
$$

where,

$$
\frac{T}{2}=\frac{L}{v}
$$

Here, $L$ is the length of the hump and $v$ is the speed of the vehicle and $T$ is the time it takes for a wheel to pass over the hump.

\section{Sinusoidal hump modelling}

The half-sine function can be converted to a sinusoidal with the same length and height by making changes. The general diagram of a sinusoidal hump is shown in Figure 2. Equation 3 shows the sinusoidal hump function [6].

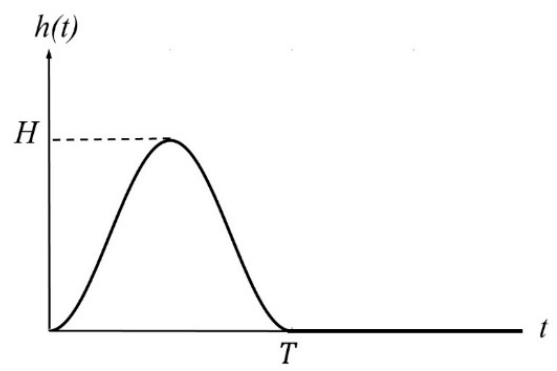

Figure 2. Geometric shape for the sinusoidal hump.

$$
h(t)= \begin{cases}\frac{H}{2} \sin \left(\frac{2 \pi\left(t-\frac{T}{4}\right)}{T}\right)+\frac{H}{2} & t \leq T \\ 0 & t>T\end{cases}
$$

Where,

$$
T=\frac{L}{v}
$$

\section{Circular hump modelling}

Here we are going to model a circular hump using mathematical functions. Figure 3 shows the general view of this hump as well as the parameters in it.

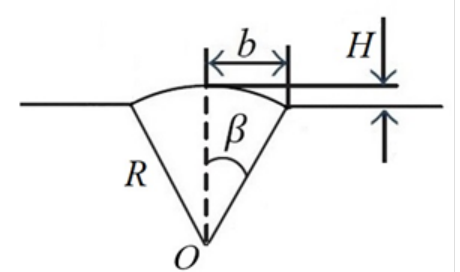

Figure 3. Geometric shape for the circular hump.

According to the Pythagorean relation, we have:

$$
b^{2}+(R-H)^{2}=R^{2} \quad \Rightarrow \quad R=\frac{H^{2}+b^{2}}{2 H}
$$

Where $R, H$ and $b$ represent the radius, height, and half of the length of the hump, respectively. We also have:

$$
\sin \beta=\frac{b}{R} \quad \Rightarrow \quad \beta=\sin ^{-1}\left(\frac{b}{R}\right)
$$

where $\beta$ is the angle between the line perpendicular to the hump and its starting edge from the flat surface of the asphalt. We knew that the car passes over the hammer at a constant speed, and this constant speed is true on the curved 
profile and not the horizontal surface, while to model the height of the hump at any time, the desired point must be displayed on the horizontal surface. For this purpose, we divide the total value of the angle into $n$ equal parts.

$$
d \alpha=\frac{\beta}{n}
$$

Where $\mathrm{n}$ is the number of points sampled from the surface of the circle profile to construct a circle curve. In fact, by dividing beta by $n$, we divide the beta angle by an equal arc. Therefore, the value of the angle of each point of the circle curve with the perpendicular line is calculated from Eq. (8)

$$
\alpha_{i+1}=\alpha_{i}-d \alpha \quad(i=1,2, \ldots, n),\left(\alpha_{1}=\beta\right)
$$

By plotting each point on the surface of the circle on a horizontal surface and relating them to the velocity relation, the time of each sampling point was calculated.

$$
t_{i+1}=t_{i}+\frac{R}{v}\left(\sin \alpha_{i}-\sin \alpha_{i+1}\right) \quad(i=1,2, \ldots, n),\left(t_{1}=0\right)
$$

We can also calculate the height of each point using Eq. (10).

$$
h_{i}=R\left(\cos \alpha_{i}-\cos \alpha_{1}\right) \quad(i=1,2, \ldots, n)
$$

It should be noted that using these relations, only the first half of the hump is modelled, but due to the symmetry of the hump relative to the vertical line, the other half is obtained in the same way [5].

\section{Trapezoidal hump modelling}

To model this type of hump, we use a trapezoidal function. The height of the hump was considered to be equal to a fixed value of $10 \mathrm{~cm}$. Figure 4 shows the general view of this hump.

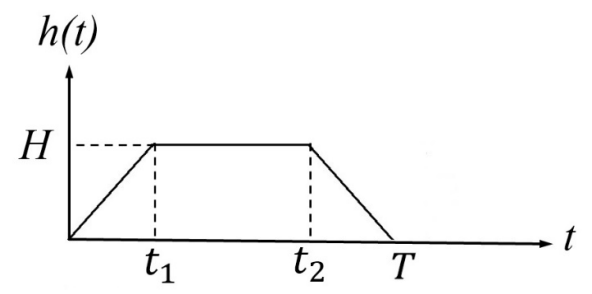

Figure 4. Geometric shape for the trapezoidal hump.

To express the start and end slope of the hump, we have used the parameter a, which is obtained from the ratio of the uphill length to the total length of the hump Eq. (11). Here, its value was considered equal to 0.2. It should be noted that the length of the uphill is equal to the downhill part. Equation 12 shows the mathematical functions of this hump.

$$
\begin{gathered}
a=\frac{t_{1}}{T}=0.2 \\
h(t)= \begin{cases}\frac{H}{t_{1}} t & t \leq t_{1} \\
H & t_{1}<t \leq t_{2} \\
\frac{H}{t_{1}-t_{2}} & t_{2}<t \leq T \\
0 & t>T\end{cases}
\end{gathered}
$$

Where

$$
T=\frac{L}{v}
$$

\section{Wheel excitation extraction}

According to the modelling performed from each profile, the vertical excitation of the front wheel $\left(z_{f d}\right)$ is calculated from the following Eq. [8].

$$
z_{f d}=F u n c(t)
$$


Where Func $(t)$ can be any of the sinusoidal, half-sine, circular or trapezoidal functions. The lag relationship between front and rear wheels can be expressed as the time lag between front tire travels over one point of the road surface and rear tire passes the same point at the same condition of speed, which can be represented as [8]:

$$
t_{d}=\frac{l_{f}+l_{r}}{v}
$$

Where $l_{f}$ and $l_{r}$ represent the distance of the centre of mass of the vehicle body from the front and rear tires, respectively, and $v$ is the vehicle speed. Therefore, rear-wheel excitation is obtained from the following equation.

$$
z_{r d}=\operatorname{Func}\left(t+t_{d}\right)
$$

\section{Vehicle Suspension Modelling}

The suspension used in this research is a half-car model with 4-DOF, which is shown in Figure 5. The springs and dampers of this model are non-linear. The model consists of unsprung masses, springs, and dampers of front and rear suspensions and tires and a rigid vehicle body. Degrees of freedom include the vertical motion of the front and rear unsprung masses and two vertical and rotational motions of the rigid vehicle body.

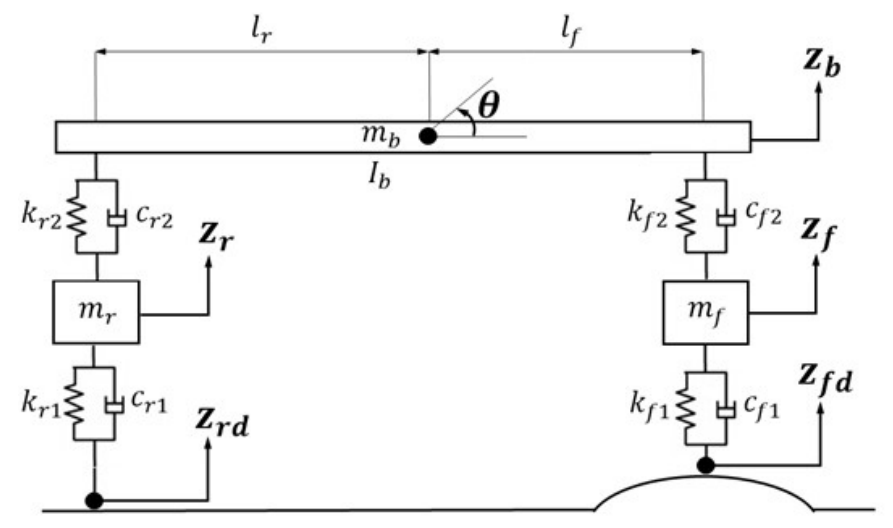

Figure 5. Non-linear 4-DOF half-car model.

The equations of motion according to Newton's second law are obtained as follows.

$$
\left\{\begin{array}{l}
m_{b} \ddot{z}=-F_{s f 2}-F_{c f 2}-F_{s r 2}-F_{c r 2}-m_{b} g \\
I_{b} \ddot{\theta}=\left(F_{s f 2}-F_{c f 2}\right) l_{f} \cos \theta-\left(F_{s r 2}-F_{c r 2}\right) l_{f} \cos \theta \\
m_{f} \ddot{z}_{f}=F_{s f 2}+F_{c f 2}-F_{s f 1}-F_{c f 1}-m_{f} g \\
m_{r} \ddot{z}_{r}=F_{s r 2}+F_{c r 2}-F_{s r 1}-F_{c r 1}-m_{r} g
\end{array}\right.
$$

Where $m_{f}$ and $m_{r}$ represent the unsprung masses of front and rear, respectively. Also, $m_{b}$ and $I_{b}$ represent the mass and moment inertia of the vehicle body, respectively. The front and rear non-linear suspension spring force are $F_{s f 2}$ and $F_{s r 2}$ respectively. $F_{c f 2}$ and $F_{c r 2}$ are front and rear non-linear suspension spring force, respectively. The front and rear nonlinear tire spring force are $F_{s f 1}$ and $F_{s r 1} . F_{c f 1}$ and $F_{c r 1}$ are front and rear non-linear tire damper force.

In this suspension system, the relationship between force and displacement for non-linear springs is as follows [8].

$$
f_{s}=k_{s} \operatorname{sgn}\left(\Delta_{s}\right)\left|\Delta_{s}\right|^{n}
$$

where $f_{s}$ is the dynamic spring force, $k_{s}$ is the stiffness coefficient of the spring, $\Delta_{s}$ is the deformation of the spring, $\operatorname{sgn}($.$) is the sign function, n$ is the non-linear coefficient of the spring. Due to the above relationship, the force of each non-linear spring in the suspension can be calculated from the following equations.

$$
\left\{\begin{array}{l}
F_{s f 1}=100^{(n f 1-1)} k_{f 1} \operatorname{sgn}\left(\Delta z_{f 1}\right)\left|\Delta z_{f 1}\right|^{n f 1} \\
F_{s f 2}=100^{(n f 2-1)} k_{f 2} \operatorname{sgn}\left(\Delta z_{f 2}\right)\left|\Delta z_{f 2}\right|^{n f 2} \\
F_{s r 1}=100^{(n r 1-1)} k_{r 1} \operatorname{sgn}\left(\Delta z_{r 1}\right)\left|\Delta z_{r 1}\right|^{n r 1} \\
F_{s r 2}=100^{(n r 2-1)} k_{r 2} \operatorname{sgn}\left(\Delta z_{r 2}\right)\left|\Delta z_{r 2}\right|^{n r 2}
\end{array}\right.
$$

Where 


$$
\left\{\begin{array}{l}
\Delta z_{f 1}=z_{f}-\Delta_{s f 1}-z_{f d} \\
\Delta z_{r 1}=z_{r}-\Delta_{s r 1}-z_{r d} \\
\Delta z_{f 1}=z_{b}-\Delta_{s f 2}-z_{f}-l_{f} \sin \theta \\
\Delta z_{f 1}=z_{b}-\Delta_{s r 2}-z_{r}+l_{r} \sin \theta
\end{array}\right.
$$

In the above relations, $\Delta_{S}$ indicates the displacement of each of the springs in the static state of the car, which will be calculated later. Also, the dumping force of the suspension system is obtained from the following general relation [8].

$$
f_{s c}=c_{s} \Delta \dot{z}_{s}
$$

Where $f_{s c}$ is the damping force, $\Delta \dot{z}_{s}$ is the relative velocity of damper and $c_{s}$ is the damping coefficient defined as expressed as

$$
c_{s}=\left\{\begin{array}{l}
c_{u}, \Delta \dot{z}_{s} \geq 0 \\
c_{d}, \Delta \dot{z}_{s}<0
\end{array}\right.
$$

Here, $c_{d}$ and $c_{u}$ are damping coefficients for compression and tension, respectively. As a result, the force of non-linear dampers is obtained from the following equations.

$$
\left\{\begin{array}{l}
F_{c f 1}=c_{f 1} \Delta \dot{z}_{f 1} \\
F_{c f 2}=c_{f 2} \Delta \dot{z}_{f 2} \\
F_{c r 1}=c_{r 1} \Delta \dot{z}_{r 1} \\
F_{c r 2}=c_{r 2} \Delta \dot{z}_{r 2}
\end{array}\right.
$$

where

$$
\left\{\begin{array}{l}
\Delta \dot{z}_{f 1}=\dot{z}_{f}-\dot{z}_{f d} \\
\Delta \dot{z}_{f 2}=\dot{z}_{b}-\dot{z}_{f}-l_{f} \dot{\theta} \cos \theta \\
\Delta \dot{z}_{r 1}=\dot{z}_{r}-\dot{z}_{r d} \\
\Delta \dot{z}_{r 2}=\dot{z}_{b}-\dot{z}_{r}+l_{r} \dot{\theta} \cos \theta
\end{array}\right.
$$

and

$$
\begin{aligned}
& c_{f 1}=\left\{\begin{array}{l}
c_{f 1 u}, \Delta \dot{z}_{f 1} \geq 0 \\
c_{f 1 d}, \Delta \dot{z}_{f 1}<0
\end{array}\right. \\
& c_{f 2}=\left\{\begin{array}{l}
c_{f 2 u}, \Delta \dot{z}_{f 2} \geq 0 \\
c_{f 2 d}, \Delta \dot{z}_{f 2}<0
\end{array}\right. \\
& c_{r 1}=\left\{\begin{array}{l}
c_{r 1 u}, \Delta \dot{z}_{r 1} \geq 0 \\
c_{r 1 d}, \Delta \dot{z}_{r 1}<0
\end{array}\right. \\
& c_{r 2}=\left\{\begin{array}{l}
c_{r 2 u}, \Delta \dot{z}_{r 2} \geq 0 \\
c_{r 2 d}, \Delta \dot{z}_{r 2}<0
\end{array}\right.
\end{aligned}
$$

where $c_{f 1}$ and $c_{r 1}$ are respectively the front and rear tire damping coefficient, $c_{f 2}$ and $c_{r 2}$ are respectively the front and rear suspension damping coefficient.

Assume that the quality of the front and rear axles are respectively $m_{b f}$ and $m_{b r}$, and

$$
\begin{aligned}
& m_{b f}=\frac{m_{b} l_{r}}{l_{f}+l_{r}} \\
& m_{b r}=\frac{m_{b} l_{f}}{l_{f}+l_{r}}
\end{aligned}
$$

When the suspension is in static equilibrium, the following relationships are established for the static force of each spring. Using these relations, the static displacement of each spring can be calculated. This parameter is denoted by $\Delta_{s}$. 


$$
\left\{\begin{array}{l}
F_{s f 1}=100^{(n f 1-1)} k_{s f 1} \operatorname{sgn}\left(\Delta_{s f 1}\right)\left|\Delta_{s f 1}\right|^{n f 1}=\left(m_{b f}+m_{f}\right) g \\
F_{s f 2}=100^{(n f 2-1)} k_{s f 2} \operatorname{sgn}\left(\Delta_{s f 2}\right)\left|\Delta_{s f 2}\right|^{n f 2}=\left(m_{b r}+m_{r}\right) g \\
F_{s r 1}=100^{(n r 1-1)} k_{s r 1} \operatorname{sgn}\left(\Delta_{s r 1}\right)\left|\Delta_{s r 1}\right|^{n r 1}=m_{b f} g \\
F_{s r 2}=100^{(n r 2-1)} k_{s r 2} \operatorname{sgn}\left(\Delta_{s r 2}\right)\left|\Delta_{s r 2}\right|^{n r 2}=m_{b r} g
\end{array}\right.
$$

where $k_{s f i}$ and $k_{s r i}$ (for $i=1,2$ ) represent the stiffness coefficient of suspension spring [8]. The definition of symbols used is given in the Appendix.

\section{Driver Body Modelling}

In this study, a biomechanical model of whole-body vibration was provided. The presented model is in a sitting position, linear, lumped-parameter and has 10-DOF. Applied vibrations on the model are in two directions of vertical and horizontal [14]. The overall structure of the model is obtained from the 9-DOF of Harsha's model [14]. Figure 6 shows the proposed model of the body. As can be seen from the figure, the head has a vertical and rotational movement and other parts have vertical and horizontal motion.

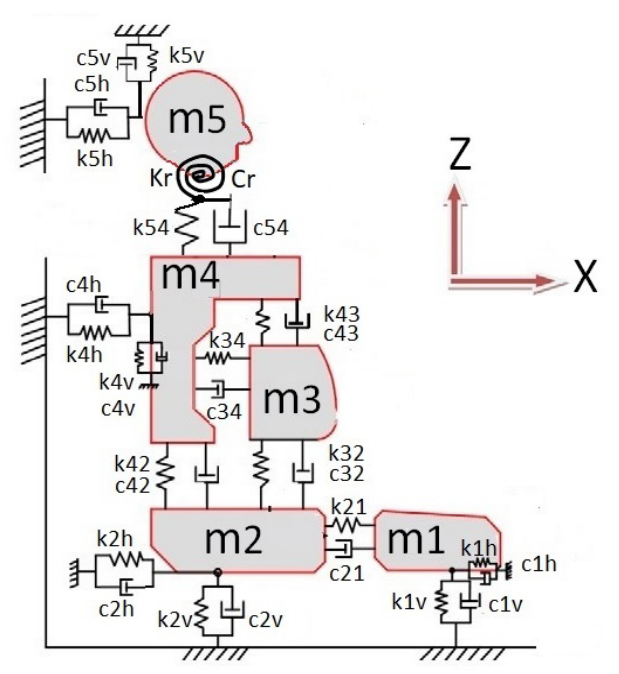

Figure 6. Linear 10-DOF biodynamic model of the human body. reproduced with permission from the Int. J. Acoust. Vib. [14].

In this model $m_{i}(i=1, \ldots, 5)$ represents the mass of each part of the body and $k_{i v}, k_{i h}, c_{i v}, c_{i h}(i=1,2,4,5)$ are the seat stiffness and damping coefficients for different points of connection with the body, respectively. $k_{i j}$ and $c_{i j}$ represents the stiffness and damping coefficients between the $i$ and $j$ masses. The definition of symbols used is given in the Appendix. The equations of motion of the passenger body are given here.

$$
\begin{gathered}
m_{1} \ddot{z}_{1}-c_{1 v} \dot{z}_{1}-k_{1 v} z_{1}=c_{1 v} \dot{z}_{0}+k_{1 v} z_{0} \\
m_{1} \ddot{x}_{1}-c_{1 h} \dot{x}_{1}-c_{21}\left(\dot{x}_{1}-\dot{x}_{2}\right)-k_{1 h} x_{1}-k_{21}\left(x_{1}-x_{2}\right)=c_{1 h} \dot{x}_{0}+k_{1 h} x_{0} \\
m_{2} \ddot{z}_{2}-c_{2 v} \dot{z}_{2}-c_{42}\left(\dot{z}_{2}-\dot{z}_{4}\right)-c_{32}\left(\dot{z}_{2}-\dot{z}_{3}\right)-k_{2 v} z_{2}- \\
k_{42}\left(z_{2}-z_{4}\right)-k_{32}\left(z_{2}-z_{3}\right)=c_{2 v} \dot{z}_{0}+k_{2 v} z_{0} \\
m_{2} \ddot{x}_{2}-c_{2 h} \dot{x}_{2}-c_{21}\left(\dot{x}_{2}-\dot{x}_{1}\right)-k_{2 h} x_{2}-k_{21}\left(x_{2}-x_{1}\right)=c_{2 h} \dot{x}_{0}+k_{2 h} x_{0} \\
m_{3} \ddot{z}_{3}-c_{32}\left(\dot{z}_{3}-\dot{z}_{2}\right)-c_{43}\left(\dot{z}_{3}-\dot{z}_{4}\right)-k_{32}\left(z_{3}-z_{2}\right)-k_{43}\left(z_{3}-z_{4}\right)=0 \\
m_{3} \ddot{x}_{3}-c_{34}\left(\dot{x}_{3}-\dot{x}_{4}\right)-k_{34}\left(x_{3}-x_{4}\right)=0 \\
m_{4} \ddot{z}_{4}-c_{42}\left(\dot{z}_{4}-\dot{z}_{2}\right)-c_{43}\left(\dot{z}_{4}-\dot{z}_{3}\right)-c_{54}\left(\dot{z}_{4}-\dot{z}_{5}\right)-c_{4 v} \dot{z}_{4} \\
k_{42}\left(z_{4}-z_{2}\right)-k_{43}\left(z_{4}-z_{3}\right)-k_{54}\left(z_{4}-z_{5}\right)-k_{4 v} z_{4}=c_{4 v} \dot{z}_{b}+k_{4 v} z_{b} \\
\left(m_{4}+m_{5}\right) \ddot{x}_{4}-c_{4 h} \dot{x}_{4}-c_{43}\left(\dot{x}_{3}-\dot{x}_{4}\right)-c_{5 h} \dot{x}_{4}-k_{4 h} x_{4}-k_{43}\left(x_{3}-x_{4}\right)-k_{5 h} x_{4}+ \\
m_{5} l \ddot{\theta}+c_{5 h} l \dot{\theta}+k_{5 h} l \theta=c_{4 h} \dot{x}_{b}+k_{4 h} x_{b}+c_{5 h} \dot{x}_{h}+k_{5 h} x_{h} \\
m_{5} \ddot{z}_{5}-c_{54}\left(\dot{z}_{5}-\dot{z}_{4}\right)-c_{5 v} \dot{z}_{5}-k_{54}\left(z_{5}-z_{4}\right)-k_{5 v} z_{5}=c_{5 v} \dot{z}_{h}+k_{5 v} z_{h}
\end{gathered}
$$




$$
\begin{aligned}
& m_{5} l \ddot{x}_{4}+c_{5 h} l \dot{x}_{4}+k_{5 h} l x_{4}+\left(I+m_{5} l^{2}\right) \ddot{\theta}+\left(c_{r}+c_{5 h} l^{2}\right) \dot{\theta}+ \\
& \left(k_{r}+k_{5 h} l^{2}+m_{5} g l\right) \theta=\left(c_{5 h} \dot{x}_{h}+k_{5 h} x_{h}\right) l
\end{aligned}
$$

\section{Coupling between Suspension System and Seat}

In this model of suspension and seat, the seat has only one degree of vertical freedom, and its rotational motion is completely dependent on the pitch motion of the sprung mass. As shown in Figure 7, the pitch motion of the seat is equal to $\theta$ and is equal to the pitch motion of the sprung mass.

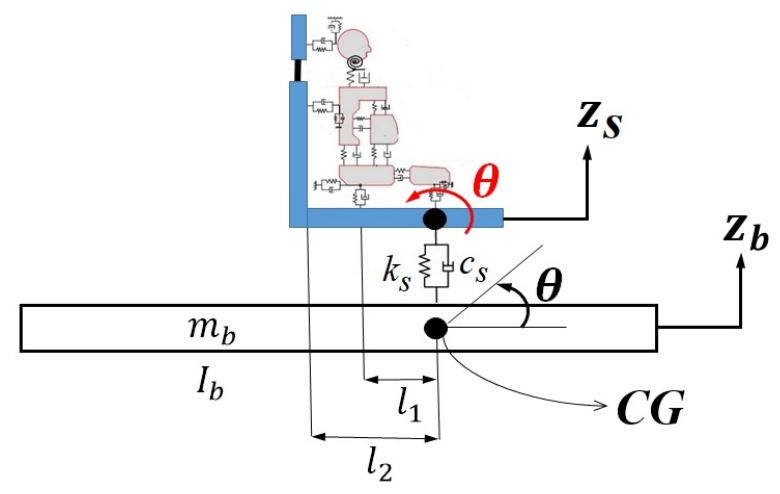

Figure 7. Schematic diagram of the biodynamic model coupled with a sprung mass.

As a result, the equation governing the vertical movement of the seat is obtained as follows.

$$
m_{S} \ddot{z}_{S}=-k_{S}\left(z_{S}-z_{b}\right)-k_{1 v}\left(z_{S}-z_{1}\right)-k_{2 v}\left(z_{S}-z_{2}\right)-k_{4 v}\left(z_{S}-z_{4}\right)-k_{5 v}\left(z_{S}-z_{5}\right)
$$

The driver model has 10-DOF, which includes five vertical and five horizontal movements. Only the inputs of the body model are given here, and the body model equations have been omitted due to their clarity and high number of them.

$$
\begin{cases}z_{0 i}=z_{s}-l_{i} \sin \theta & i=1,2 \\ x_{0 i}=l_{i}(1-\cos \theta) & i=1,2\end{cases}
$$

where $z_{s}$, is the vertical displacement of the seat, $\theta$ is the pitch movement of the sprung mass and $l_{i}$ is the distance from each point of the body to the center of mass of the suspension system.

According to the two equations, it can be seen that in the contact between the seat and the body, it is the basic pitch motion that causes horizontal acceleration in the body. To derive horizontal equations of the body, the model can be considered as Figure 8. Because the horizontal displacement of the body is completely dependent on the sprung mass and the seat force shows itself only in the vertical movement of the body.

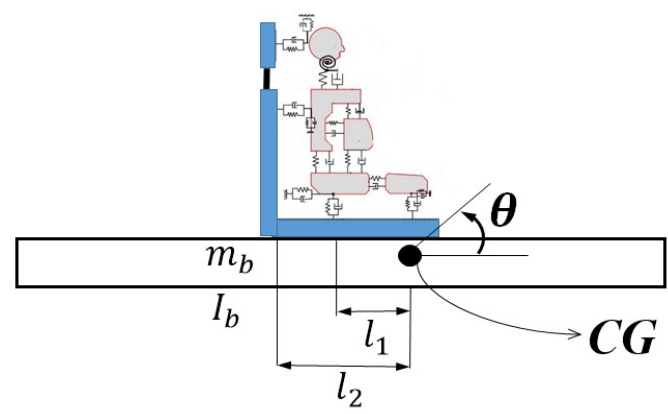

Figure 8. Schematic diagram of the biodynamic model coupled with a sprung mass.

In total, it can be said that the model has 4-DOF for the suspension, 1-DOF of the seat, and 10-DOF of the driver's body, which includes a total of 15-DOF.

\section{Optimisation of Humps}

To optimise the humps, their height was kept constant at $10 \mathrm{~cm}$, and the length of the humps was a variable that was optimised. According to the standards, the length of the humps is considered between 3 and $4.5 \mathrm{~m}$. For this purpose, the objective function was obtained as the average of horizontal and vertical RMS accelerations at speeds of 10 to 60 . To compare the results of head accelerations at any speed, the root mean square of the accelerations is used [14]. This value is obtained from Equation 44. 


$$
a_{R M S}=\sqrt{\frac{1}{n} \sum_{i=1}^{n} a_{i}{ }^{2}}
$$

The relation of the objective function was considered as follows.

$$
y=0.5 \operatorname{mean}\left(\operatorname{RMS}\left(a_{z}\right)\right)+0.5 \operatorname{mean}\left(\operatorname{RMS}\left(a_{x}\right)\right)
$$

\section{RESULTS AND DISCUSSION}

In this study, MATLAB software was used to solve the model numerically. The parameters of the half-car and biodynamic models that are used in the numerical study are shown in Table 1 and Table 2 [8].

Table 1. Car parameters for numerical simulation [8].

\begin{tabular}{lccccc}
\hline Parameter & Unit & Value & Parameter & Unit & Value \\
\hline$m_{b}$ & $\mathrm{~kg}$ & 1180 & $k_{f 2}$ & $\mathrm{~N} / \mathrm{m}$ & 36952 \\
$m_{f}$ & $\mathrm{~kg}$ & 50 & $k_{r 2}$ & $\mathrm{~N} / \mathrm{m}$ & 30130 \\
$m_{r}$ & $\mathrm{~kg}$ & 45 & $c_{f 1}$ & $\mathrm{~kg} / \mathrm{s}$ & 10 \\
$I_{b}$ & $\mathrm{~kg} \cdot \mathrm{m}^{2}$ & 633.615 & $c_{r 1}$ & $\mathrm{~kg} / \mathrm{s}$ & 10 \\
$l_{f}$ & $\mathrm{~m}$ & 1.123 & $c_{f 2 u}$ & $\mathrm{~kg} / \mathrm{s}$ & 500 \\
$l_{r}$ & $\mathrm{~m}$ & 1.377 & $c_{f 2 d}$ & $\mathrm{~kg} / \mathrm{s}$ & 359.7 \\
$H$ & $\mathrm{~m}$ & 0.1 & $c_{r 2 u}$ & $\mathrm{~kg} / \mathrm{s}$ & 500 \\
$l_{1}$ & $\mathrm{~m}$ & 0.3 & $c_{r 2 d}$ & $\mathrm{~kg} / \mathrm{s}$ & 359.7 \\
$l_{2}$ & $\mathrm{~m}$ & 0.4 & $n_{f 1}$ & - & 1.25 \\
$g$ & $\mathrm{~N} / \mathrm{kg}$ & 9.81 & $n_{r 1}$ & - & 1.25 \\
$k_{f 1}$ & $\mathrm{~N} / \mathrm{m}$ & 140000 & $n_{f 2}$ & - & 1.5 \\
$k_{r 1}$ & $\mathrm{~N} / \mathrm{m}$ & 140000 & $n_{r 2}$ & - & 1.5 \\
\hline
\end{tabular}

Table 2. Biodynamic model parameters for numerical simulation [14].

\begin{tabular}{lccccc}
\hline Parameter & Unit & Value & Parameter & Unit & Value \\
\hline$m_{1}$ & $\mathrm{~kg}$ & 15.13 & $m_{5}$ & $\mathrm{~kg}$ & 6.04 \\
$m_{2}$ & $\mathrm{~kg}$ & 8.95 & $m_{s}$ & $\mathrm{~kg}$ & 20 \\
$m_{3}$ & $\mathrm{~kg}$ & 12.92 & $I_{h}$ & $\mathrm{~kg} \cdot \mathrm{m}^{2}$ & 0.02497 \\
$m_{4}$ & $\mathrm{~kg}$ & 20 & $l_{h}$ & $\mathrm{~m}$ & 0.1727 \\
$k_{1 v}$ & $\mathrm{~N} / \mathrm{m}$ & 1600 & $c_{1 v}$ & $\mathrm{Ns} / \mathrm{m}$ & 104.35 \\
$k_{1 h}$ & $\mathrm{~N} / \mathrm{m}$ & 15 & $c_{1 h}$ & $\mathrm{Ns} / \mathrm{m}$ & 14 \\
$k_{2 v}$ & $\mathrm{~N} / \mathrm{m}$ & 151625 & $c_{2 v}$ & $\mathrm{Ns} / \mathrm{m}$ & 47 \\
$k_{2 h}$ & $\mathrm{~N} / \mathrm{m}$ & 905 & $c_{2 h}$ & $\mathrm{Ns} / \mathrm{m}$ & 15 \\
$k_{4 v}$ & $\mathrm{~N} / \mathrm{m}$ & 17200 & $c_{4 v}$ & $\mathrm{Ns} / \mathrm{m}$ & 324.5 \\
$k_{4 h}$ & $\mathrm{~N} / \mathrm{m}$ & 2300 & $c_{4 h}$ & $\mathrm{Ns} / \mathrm{m}$ & 154 \\
$k_{5 v}$ & $\mathrm{~N} / \mathrm{m}$ & 17200 & $c_{5 v}$ & $\mathrm{Ns} / \mathrm{m}$ & 324.5 \\
$k_{5 h}$ & $\mathrm{~N} / \mathrm{m}$ & 2300 & $c_{5 h}$ & $\mathrm{Ns} / \mathrm{m}$ & 154 \\
$k_{21}$ & $\mathrm{~N} / \mathrm{m}$ & 2300 & $c_{21}$ & $\mathrm{Ns} / \mathrm{m}$ & 61 \\
$k_{32}$ & $\mathrm{~N} / \mathrm{m}$ & 177934 & $c_{32}$ & $\mathrm{Ns} / \mathrm{m}$ & 4464.47 \\
$k_{42}$ & $\mathrm{~N} / \mathrm{m}$ & 7628.02 & $c_{42}$ & $\mathrm{Ns} / \mathrm{m}$ & 832.77 \\
$k_{43}$ & $\mathrm{~N} / \mathrm{m}$ & 748859 & $c_{43}$ & $\mathrm{Ns} / \mathrm{m}$ & 14440.20 \\
$k_{54}$ & $\mathrm{~N} / \mathrm{m}$ & 5123.28 & $c_{54}$ & $\mathrm{Ns} / \mathrm{m}$ & 137.6 \\
$k_{34}$ & $\mathrm{~N} / \mathrm{m}$ & 25000 & $c_{34}$ & $\mathrm{Ns} / \mathrm{m}$ & 266 \\
$k_{r}$ & $\mathrm{~N} / \mathrm{m}$ & 772.4 & $c_{r}$ & $\mathrm{Ns} / \mathrm{m}$ & 18.9 \\
\hline
\end{tabular}

Here we have the result of modelling different profiles for the length of the $3.5 \mathrm{~m}$ hump at a speed of 10 meters per second. The height of the hump in all profiles is $10 \mathrm{~cm}$. We also extracted the results of these curves at higher speeds, for example, the graph at $60 \mathrm{~km} / \mathrm{h}$ is also shown in Figure 9. The number of sampled points at both speeds is equal, but due to the high speed in the second figure, the points appear to be more space. 

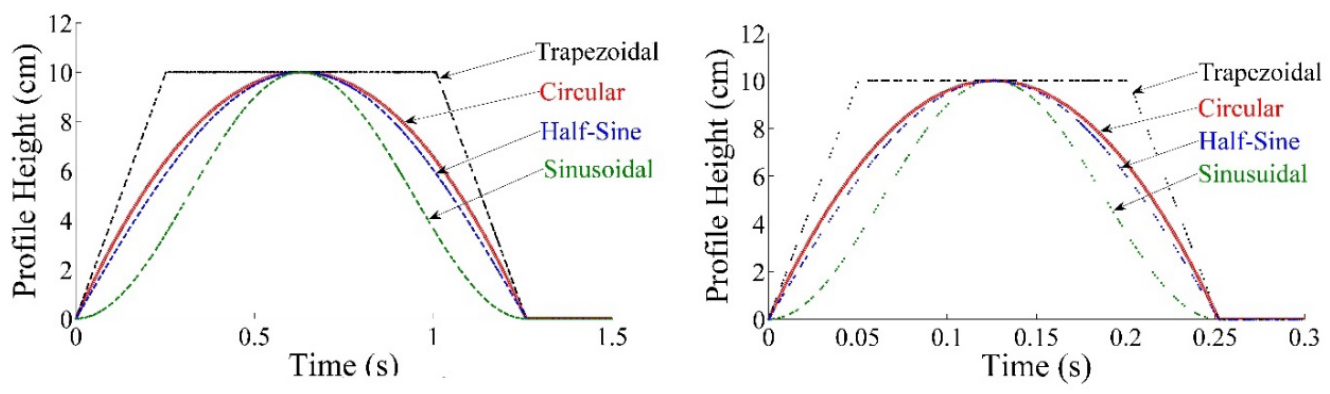

Figure 9. Trapezoidal, sinusoidal, half-sine and circular humps (a) v=10 km/h (b) v=60 km/h.

\section{Comparison of Circular and Half-Sine Humps}

Here we have extracted the results of simulating circular and half-sinusoidal profiles with a length of $3.5 \mathrm{~m}$ at speeds of 10 and $60 \mathrm{~km} / \mathrm{h}$. So we can compare them together. As can be seen from Figure 10, the result of modelling these two profiles is very close to each other. In the mathematical modelling of circle profiles, performing calculations using circle profiles is very time consuming and complicated because the time parameter does not appear explicitly with it. The reason for this is that the distances of the sampling points on the horizontal axis (time) are not equal. The constant speed of the car on the hump means equal distances on the curve and not the horizontal axis, and the need to image the points on the hump curve on the horizontal axis of time. While in the sine function, the time parameter appears explicitly and due to the distances equal to the sampling points, working with the sine function is much easier in this regard. We performed these calculations to compare two circular and half-sine profiles, and according to the results of horizontal and vertical acceleration, we concluded that in similar modelling, instead of using the circular model, the half-sine model, which is directly related to time. It is connected and easier to work with. The importance of this becomes clear when there is a need to optimise issues in this area. In Figure 11, the root mean squares of the horizontal and vertical acceleration for the two types of circular and half-sine profiles, which are $3.5 \mathrm{~m}$ long, are obtained at different speeds.
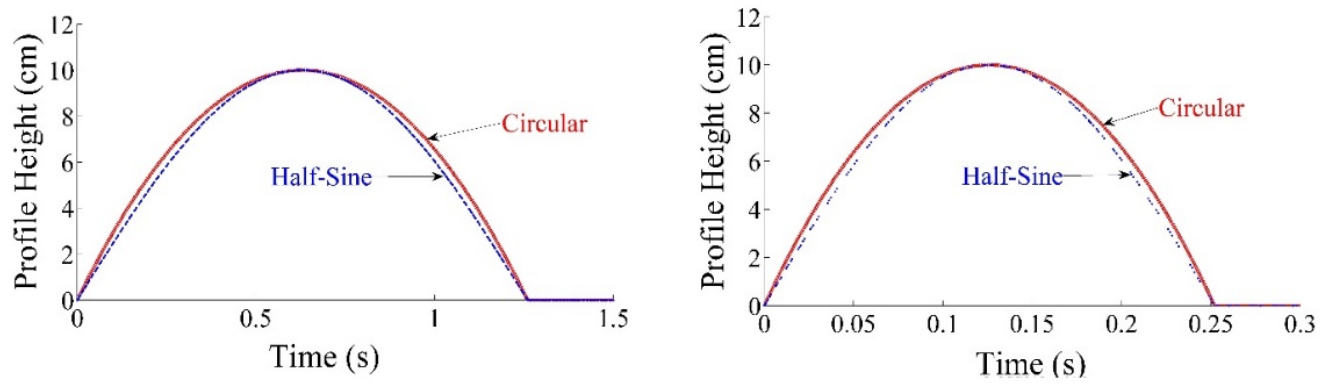

Figure 10. Half-sine and circular humps (a) $v=10 \mathrm{~km} / \mathrm{h}$ (b) $\mathrm{v}=60 \mathrm{~km} / \mathrm{h}$.

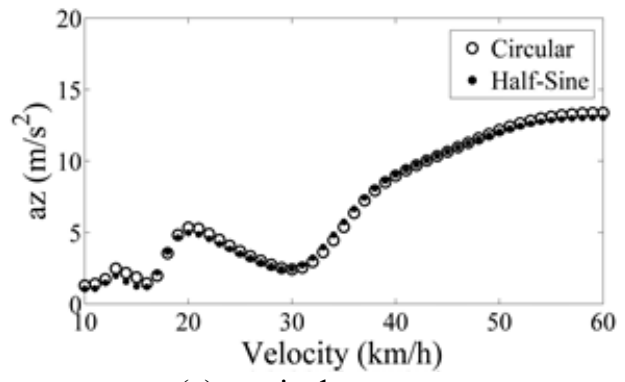

(a) vertical

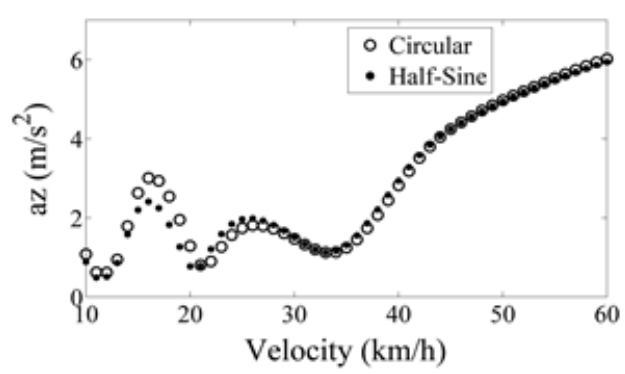

(c) vertical

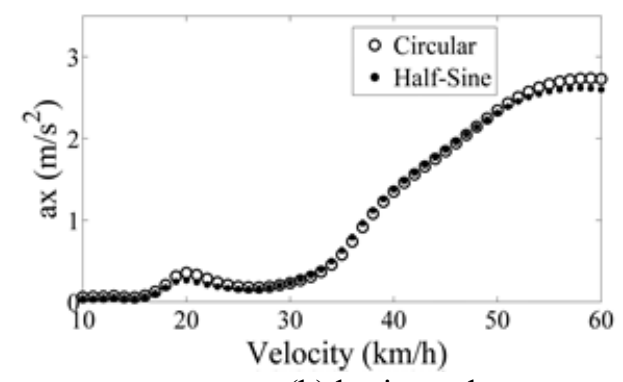

(b) horizontal

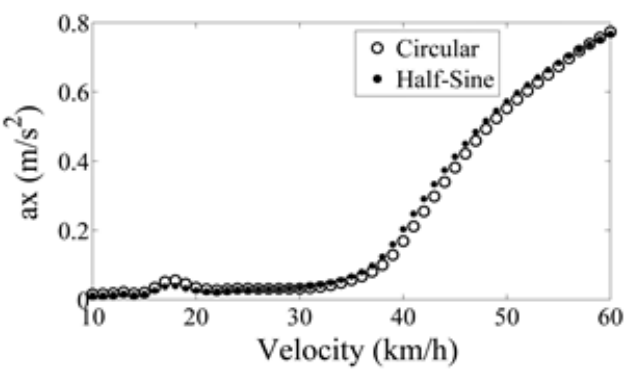

(d) horizontal

Figure 11. Head RMS acceleration for (a), (b) $\mathrm{L}=3.5 \mathrm{~m}$, and (c), (d) $\mathrm{L}=4.5 \mathrm{~m}$. 
These results are also obtained for the hump with a length of $4.5 \mathrm{~m}$. According to the results shown in Figure 11(c) and 11(d), the horizontal and vertical acceleration values for both circular and half-sine profiles are close to each other. Therefore, from now on, half-sine profiles are used instead of circular profiles in modelling.

\section{MODELLING RESULTS AND OPTIMISATION}

In this section, the results of optimising the bumps are given. The optimised parameter is the bump length. As mentioned earlier, the length of the SCHs is between 3 and $4.5 \mathrm{~m}$ and the height of all SCHs is equal to $10 \mathrm{~cm}$. In the optimisation of the sinusoidal hump, the optimal length is $4.4 \mathrm{~m}$. It should be noted that the initial value of the hump length was $3.5 \mathrm{~m}$. For a half-sine and trapezoidal hump, the optimal length is $4.3 \mathrm{~m}$. In the trapezoidal hump, the slope of the beginning and end of the hump was kept constant due to the need to comply with the standards. Figures 12(a) to 12(f) show the acceleration values of the humps before and after the optimisation.

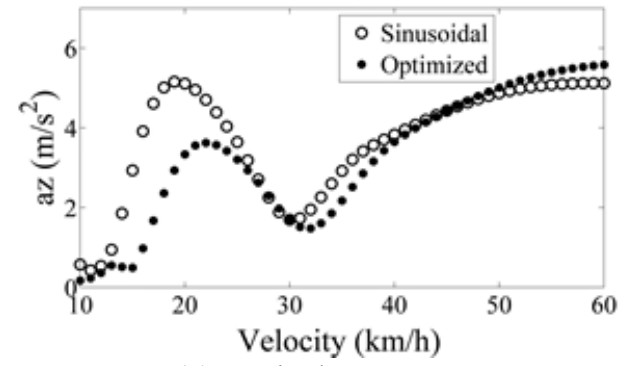

(a) vertical

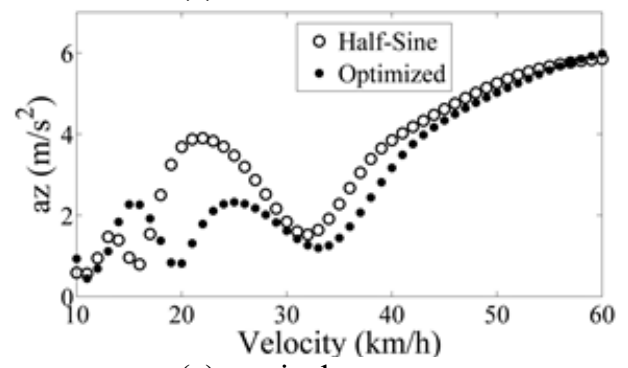

(c) vertical

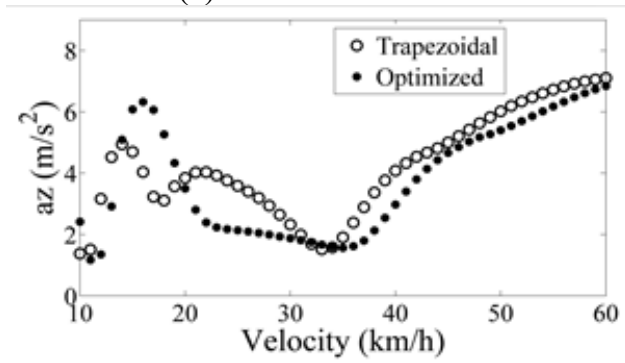

(e) vertical

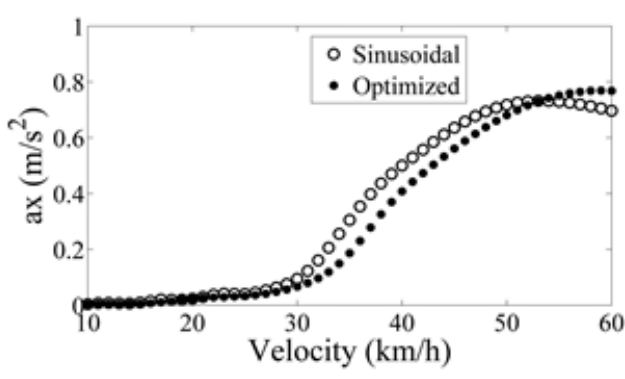

(b) horizontal

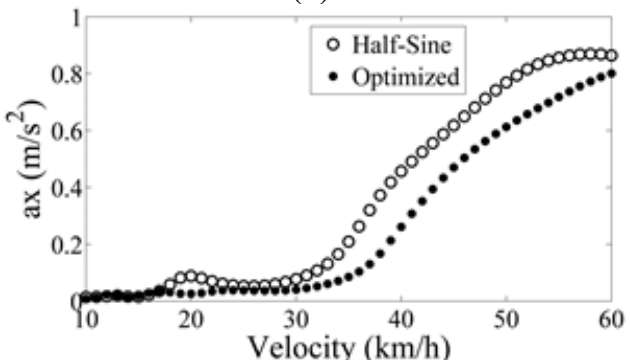

(d) horizontal

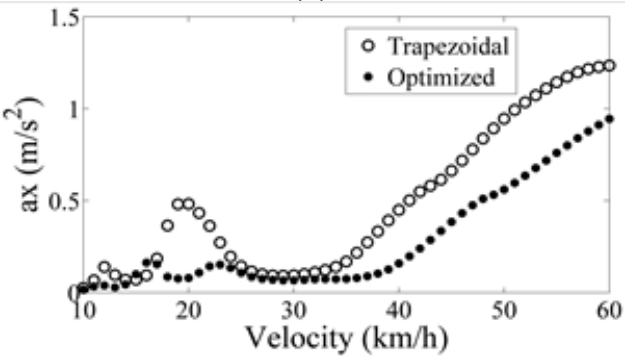

(f) horizontal

Figure 12. Head RMS acceleration of (a), (b) sinusoidal hump, (c), (d) half-sin hump, and (e), (f) trapezoidal hump before and after optimisation.

As can be seen from Figure 12(e) and 12(f), although optimisation at speeds below $20 \mathrm{~km} / \mathrm{h}$ has worsened the acceleration of this hump, but at higher speeds, the acceleration has decreased significantly. In the horizontal head acceleration diagram, the acceleration is also reduced at all speeds.

According to the acceleration diagrams, the three types of humps have a relative maximum at a speed of about $22 \mathrm{~km} / \mathrm{h}$. In this section, the head acceleration diagram in terms of time at this speed is drawn for all three types of humps. Figures 13(a) to 13(f), show the head acceleration values before and after optimisation at a speed of $22 \mathrm{~km} / \mathrm{h}$.

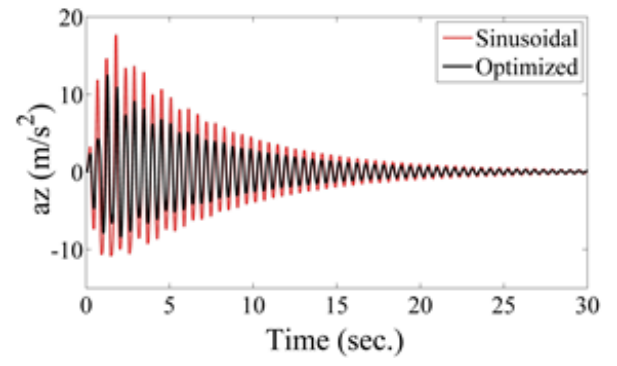

(a) vertical

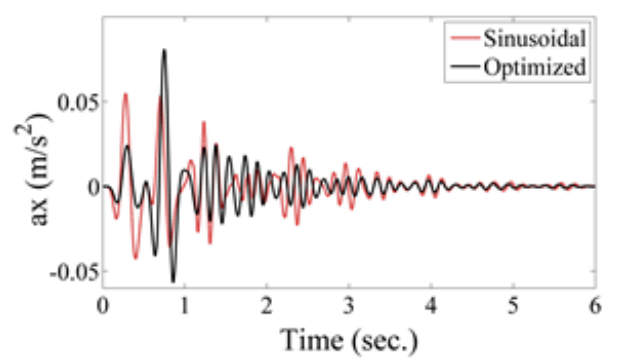

(b) horizontal 


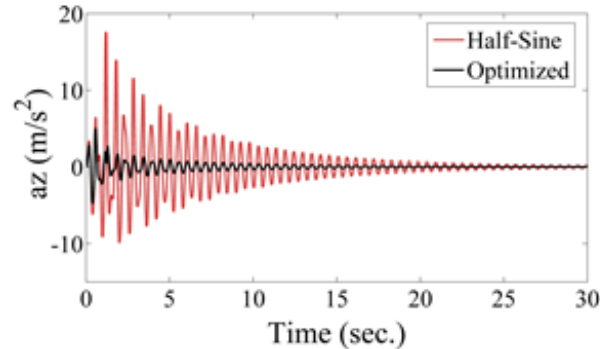

(c) vertical

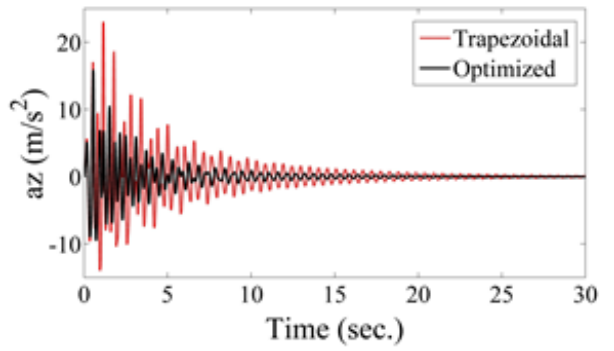

(e) vertical

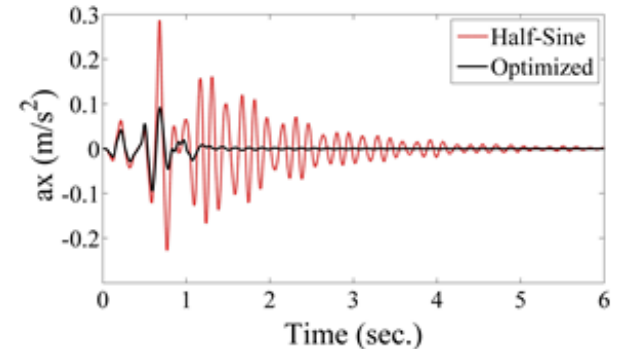

(d) horizontal

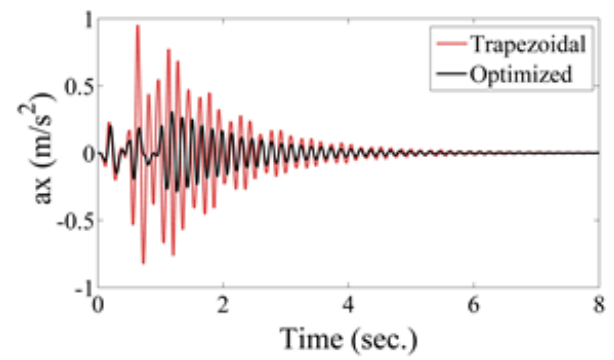

(f) horizontal

Figure 13. Head acceleration of (a), (b) sinusoidal hump, (c) (d) half-sin hump, and (e), (f) trapezoidal hump before and after of optimisation.

The power spectrum of a time series describes the distribution of power into frequency components composing that signal. According to Fourier analysis, any physical signal can be decomposed into a number of discrete frequencies or a spectrum of frequencies over a continuous range. The statistical average of a certain signal or sort of signal (including noise) as analysed in terms of its frequency content, is called its spectrum. When the energy of the signal is concentrated around a finite time interval, especially if its total energy is finite, one may compute the energy spectral density. More commonly used is the power spectral density (or simply power spectrum), which applies to signals existing over all time, or over a time period large enough (especially in relation to the duration of measurement) that it could as well have been over an infinite time interval. In the general case, the units of PSD is the ratio of units of variance per unit of frequency. So, for example, a series of displacement values (in meters) over time (in seconds) will have PSD in units of $\mathrm{m}^{2} / \mathrm{Hz}$. Units of $\mathrm{m}^{2} \mathrm{~s}^{-2} \mathrm{~Hz}^{-1}$ are used for the PSD of acceleration [15]. Graphs of this parameter are obtained for all three types of humps at a speed of $22 \mathrm{~km} / \mathrm{h}$. According to Figure 14(a) to 14(f), it can be said that the power spectral density at all frequencies has decreased for all three types of humps.

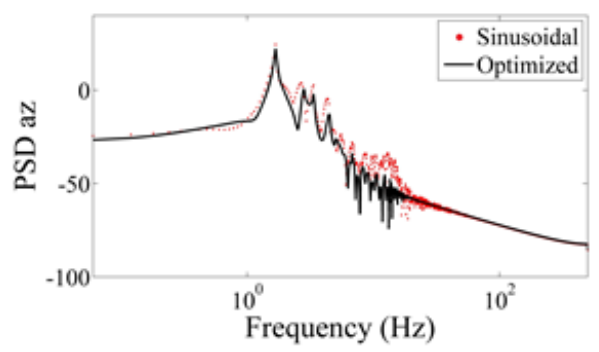

(a) vertical

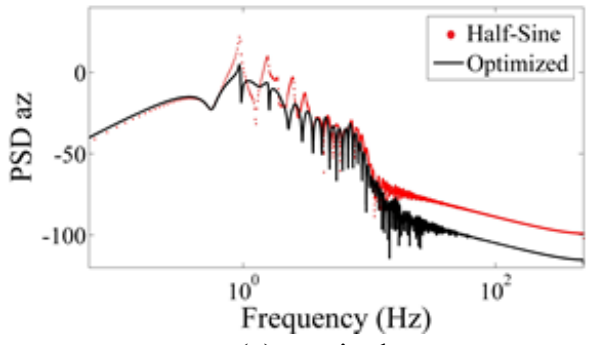

(c) vertical

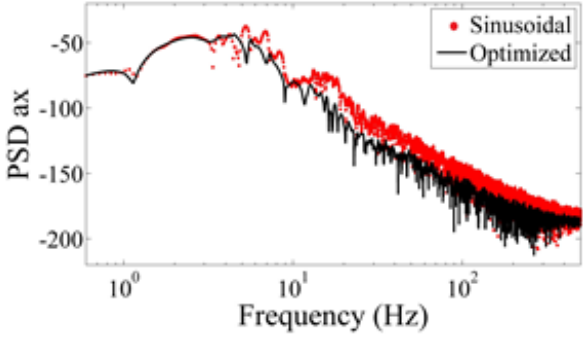

(b) horizontal

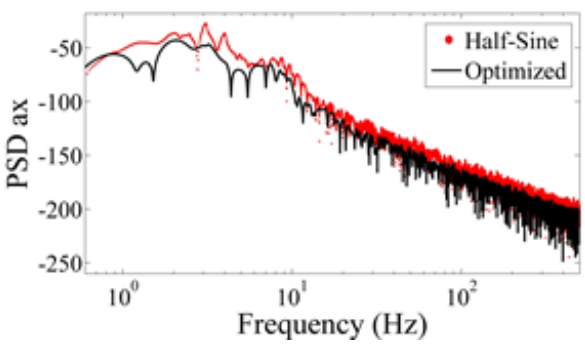

(d) horizontal 


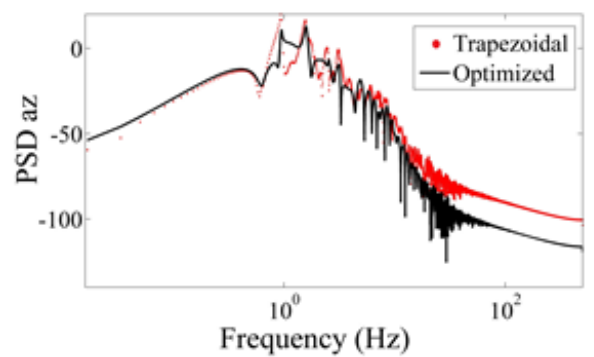

(e) vertical

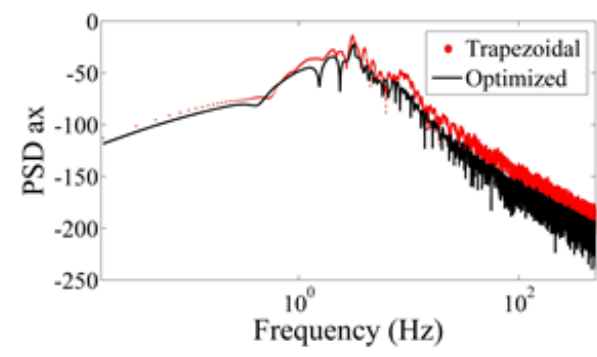

(f) horizontal

Figure 14. Power spectral density of (a), (b) sinusoidal hump, (c), (d) half-sine hump, and (e), (f) trapezoidal hump before and after of optimisation.

\section{CONCLUSION}

Speed control humps are used in different parts of the road to reduce the speed of cars. When the car passes over the hump, the driver's head has vertical and horizontal acceleration, and high values of these accelerations can reduce the driver's comfort. The purpose of this study was to optimise the types of humps by considering the vertical and horizontal acceleration of the head. In previous researches, the main focus was only on vertical acceleration, but in this study, horizontal head acceleration was also considered. The modelling was performed by a non-linear suspension system (4DOF) with a driver biodynamic model (10-DOF). The humps studied were circular, sinusoidal, half-sinusoidal, and trapezoidal. In this study, it was shown that the acceleration values for circular and half-sinusoidal bumps at all speeds are quite close to each other and one of them can be used in modelling. The results of optimising the length of the humps showed a significant reduction in horizontal and vertical acceleration at all speeds. From this modelling, it is also possible to extract a suitable range for passing the speed of cars over different types of hump.

\section{ACKNOWLEDGEMENT}

We thank Professor Jorge P. Arenas, Editor-in-Chief of the International Journal of Acoustics and Vibration for permission to republish Figure 6 in this article.

\section{REFERENCES}

[1] J. P. Hessling and P. Zhu, "Analysis of vehicle rotation during passage over speed control road humps," in Proceedings International Conference on Intelligent Computation Technology and Automation, ICICTA 2008, 2008, vol. 1, pp. 304-308, doi: 10.1109/ICICTA.2008.311.

[2] M. M. ElMadany and A. O. Qarmoush, "Dynamic analysis of a slow-active suspension system based on a full car model," J. Vib. Control, vol. 17, no. 1, pp. 39-53, Jan. 2011, doi: 10.1177/1077546309352828.

[3] Z. Yang et al., "Chaotic vibration and comfort analysis of non-linear full-vehicle model excited by consecutive speed control humps," Math. Probl. Eng., vol. 2014, pp. 370634, 2014, doi: 10.1155/2014/370634.

[4] C. Berthod and C. Leclerc, "Traffic calming in Québec: Speed humps and speed cushions," J. Civ. Eng. Archit., vol. 7, no. 4, pp. 456-465, 2013, doi: 10.17265/1934-7359/2013.04.009.

[5] D. Garcia-Pozuelo et al., "Bump modelling and vehicle vertical dynamics prediction," Adv. Mech. Eng, vol. 6, 2014, doi: $10.1155 / 2014 / 736576$.

[6] A.C. Mitra et al., "Optimisation of passive vehicle suspension system by genetic algorithm," in Procedia Eng., Jan. 2016, vol. 144, pp. 1158-1166, doi: 10.1016/j.proeng.2016.05.087.

[7] D. Koulocheris, G. Papaioannou, and D. Christodoulou, "Assessment of the optimisation procedure for the non-linear suspension system of a heavy vehicle," International Journal for Vehicle Mechanics , Engines and Transportation Systems, vol. 42, no. 2, pp. 19-35, 2016.

[8] Z. Yang et al., "Vibration suppression of four degree-of-freedom non-linear vehicle suspension model excited by the consecutive speed humps," J. Vib. Control, vol. 22, no. 6, pp. 1560-1567, Apr. 2016, doi: 10.1177/1077546314543728.

[9] M. M. Elmadany and M. I. Al-Majed, "Quadratic synthesis of active controls for a quarter-car model," J. Vib. Control, vol. 7, no. 8, pp. 1237-1252, Nov. 2001, doi: 10.1177/107754630100700806.

[10] C. C. Liang and C. F. Chiang, "A study on biodynamic models of seated human subjects exposed to vertical vibration," Int. J. Ind. Ergon., vol. 36, no. 10, pp. 869-890, Oct. 2006, doi: 10.1016/j.ergon.2006.06.008.

[11] R. Desai, A. Guha, and P. Seshu, "Multibody biomechanical modelling of human body response to vibrations in an automobile," In Mechanisms and Machine Science, Uhl T. Eds. Cham: Springer, 2019, pp- 3-12.

[12] B. W. Huang, et al. "Human cranium dynamic analysis," Life Science Journal, vol. 6, no. 4, pp. 15-22, 2009.

[13] H. Gheibollahi, M. Masih-Tehrani, and M. Niroobakhsh, "The key role of headrest optimisation in driver comfort," Int. J. Acoust. Vib., vol. 24, no. 3, pp. 592-599, 2019, doi: 10.20855/ijav.2019.24.31417.

[14] S.P. Harsha et al., "Measurement and bio-dynamic model development of seated human subjects exposed to low frequency vibration environment," Int. J. Veh. Noise Vib., vol. 10, no. 1/2, p. 1, 2014, doi: 10.1504/IJVNV.2014.059627.

[15] P. Stoica and R. Moses, Spectral analysis of signals. New Jersey: Prentice Hall, 2005 


\section{APPENDIX}

\section{Matlab Codes}

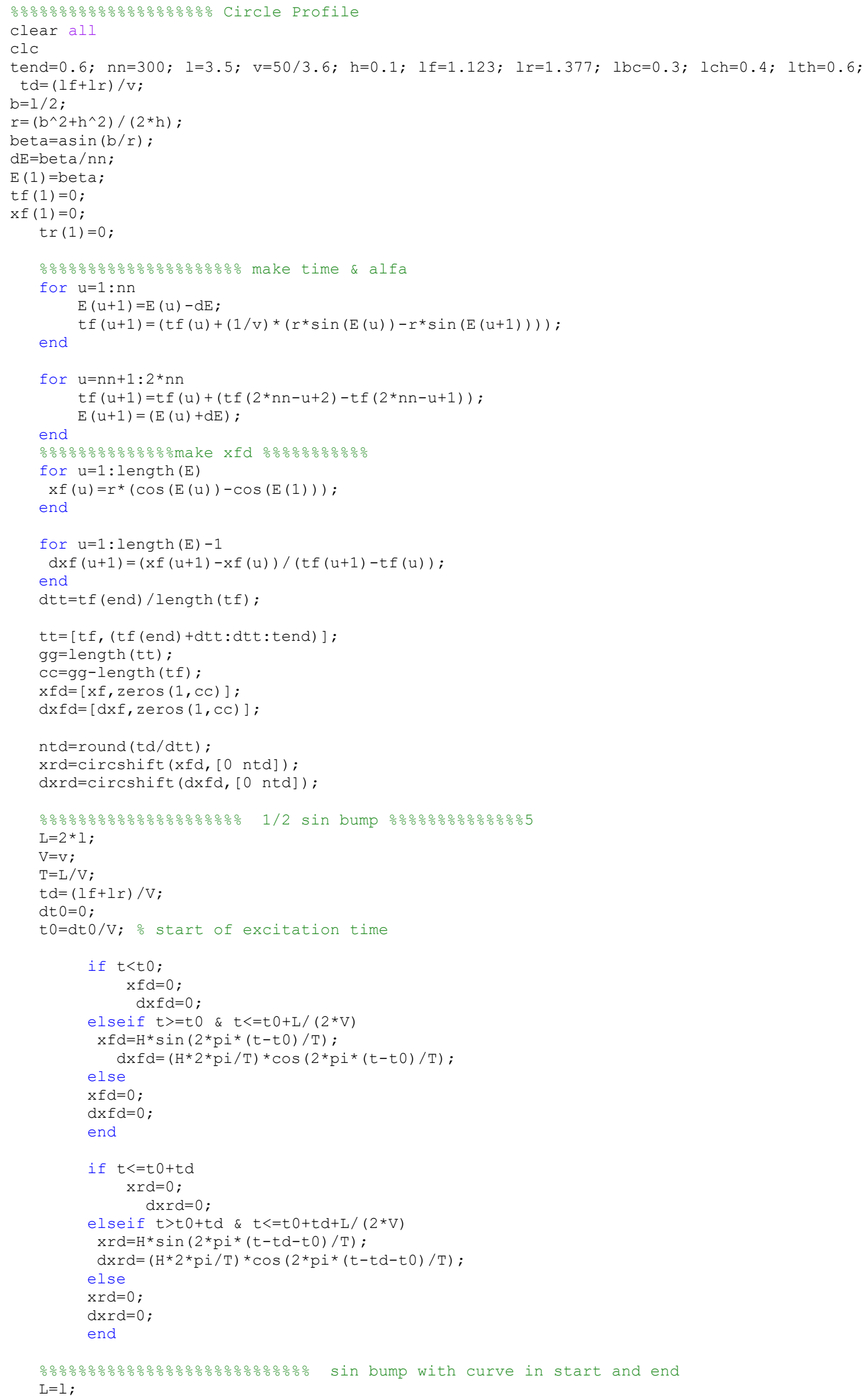




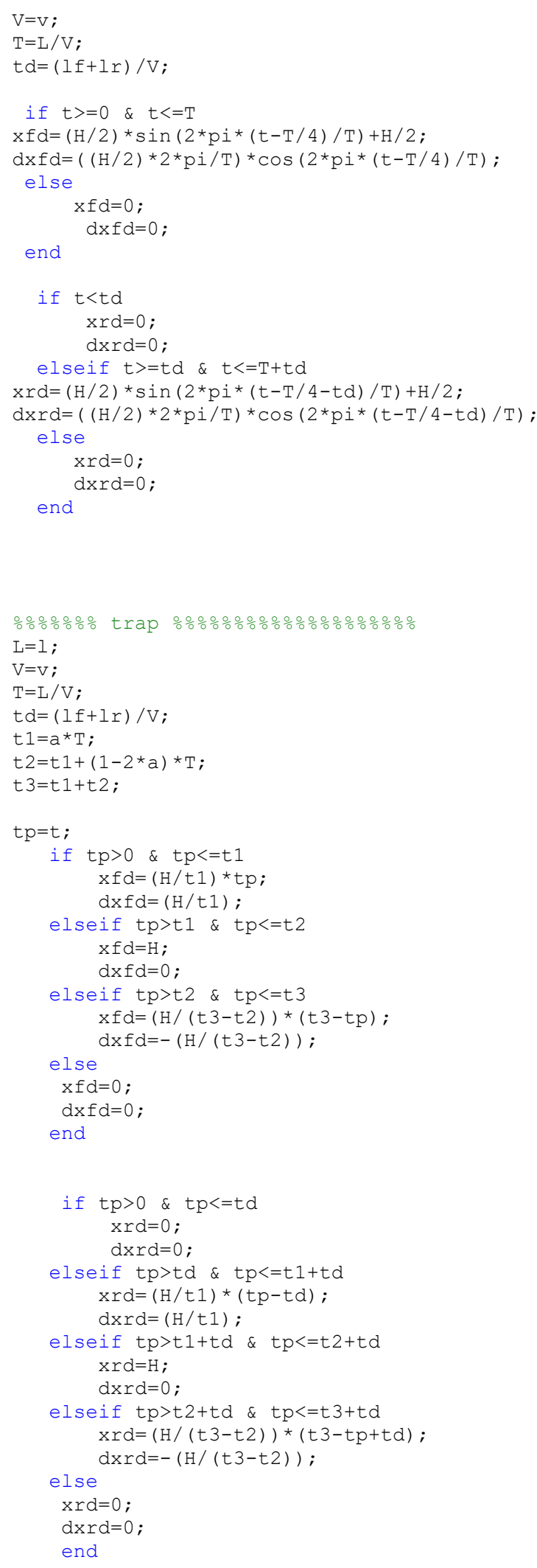




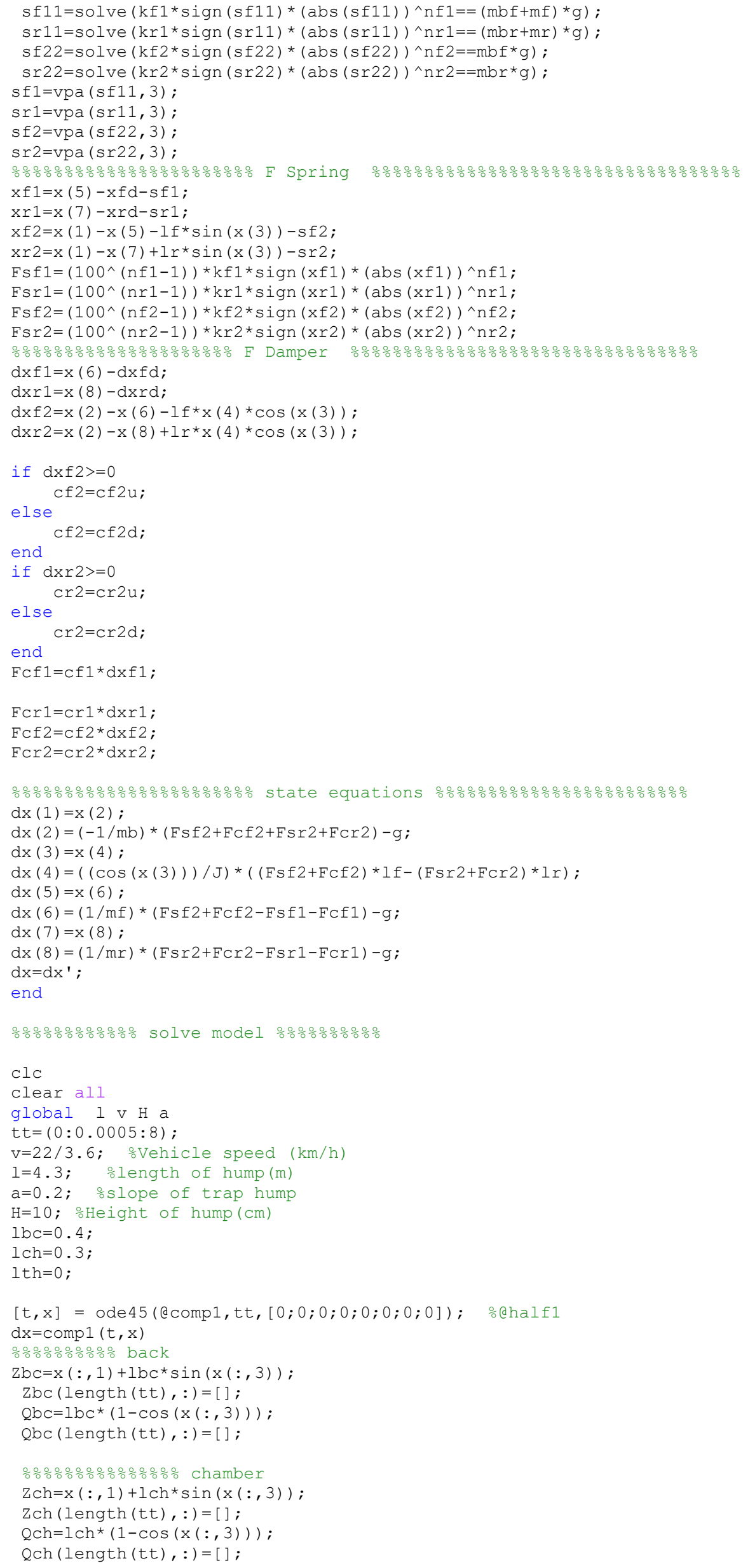




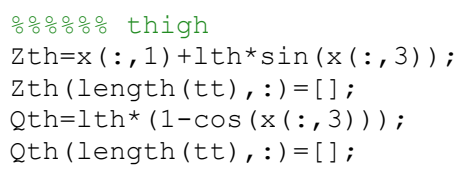

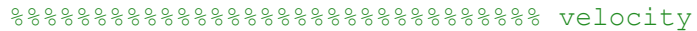

$\div \frac{0}{0} \div \circ \circ \mathrm{back}$

$\mathrm{dZbc}=\mathrm{x}(:, 2)+1 \mathrm{bc}^{\star} \mathrm{x}(:, 4) \cdot{ }^{*} \cos (\mathrm{x}(:, 3))$;

dZbc (length $(t t),:)=[]$;

$\mathrm{dQbc}=-1 \mathrm{bc} * x(:, 4) \cdot{ }^{*} \sin (\mathrm{x}(:, 3))$

$\mathrm{dQbc}($ length $(t \mathrm{t}),:)=[]$;

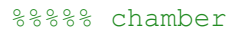

$\mathrm{dZch}=\mathrm{x}(:, 2)+1 \mathrm{ch}{ }^{\star} \mathrm{x}(:, 4) .{ }^{\star} \cos (\mathrm{x}(:, 3))$;

dZch (length $($ tt $),:)=[]$;

$d Q \operatorname{ch}=-1 \operatorname{ch}{ }^{*} x(:, 4) \cdot{ }^{*} \sin (x(:, 3))$,

dQch (length $(t t),:)=[]$;

응음응 thigh

$\operatorname{dzth}=x(:, 2)+l t h{ }^{\star} x(:, 4) .{ }^{\star} \cos (x(:, 3))$;

dzth (length $($ tt $),:)=[]$;

dQth $=-1$ th ${ }^{*} x(:, 4) \cdot{ }^{*} \sin (x(:, 3))$;

$\operatorname{dQth}($ length $($ tt $),:)=[]$;

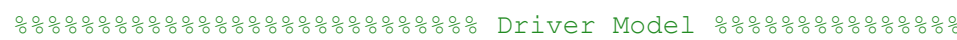

$\mathrm{m} 1=15.13 ; \mathrm{m} 2=8.95 ; \mathrm{m} 3=12.92 ; \mathrm{m} 4=20 ; \mathrm{m} 5=6.04 ; \mathrm{k} 1 \mathrm{v}=1600 ; \mathrm{k} 1 \mathrm{~h}=15 ; \mathrm{k} 2 \mathrm{v}=151625 ; \mathrm{k} 2 \mathrm{~h}=905 ; \mathrm{k} 4 \mathrm{v}=17200 ;$ $\mathrm{k} 4 \mathrm{~h}=2300 ; \mathrm{k} 5 \mathrm{v}=\mathrm{k} 4 \mathrm{v} ; \mathrm{k} 5 \mathrm{~h}=\mathrm{k} 4 \mathrm{~h} ; \mathrm{k} 21=2300 ; \mathrm{k} 32=177934 ; \mathrm{k} 42=7628.02 ; \mathrm{k} 43=748895 ; \mathrm{k} 54=5123.28 ; \mathrm{k} 34=25000 ;$ $\mathrm{c} 1 \mathrm{v}=104.35 ; \mathrm{c} 1 \mathrm{~h}=14 ; \mathrm{c} 2 \mathrm{v}=47 ; \mathrm{c} 2 \mathrm{~h}=15 ; \mathrm{c} 4 \mathrm{v}=334.5 ; \mathrm{c} 4 \mathrm{~h}=154 ; \mathrm{c} 5 \mathrm{v}=\mathrm{c} 4 \mathrm{v} ; \mathrm{c} 5 \mathrm{~h}=\mathrm{c} 4 \mathrm{~h} ; \mathrm{c} 21=61 ; c 32=4464.47 ;$ $c 42=832.77 ; c 43=14440.20 ; c 54=137.6 ; c 34=266 ; c r=18.9 ; \mathrm{kr}=772.4 ; \mathrm{I}=0.02497 ; \mathrm{lh}=0.1727 ; g=9.8 ;$ $\mathrm{N}=[\mathrm{m} 1, \mathrm{~m} 1, \mathrm{~m} 2, \mathrm{~m} 2, \mathrm{~m} 3, \mathrm{~m} 3, \mathrm{~m} 4, \mathrm{~m} 4, \mathrm{~m} 5, \mathrm{~m} 5]$ ';

$\mathrm{z}=$ length $(\mathrm{N})$;

$\mathrm{M}=\operatorname{zeros}(\mathrm{z}, \mathrm{z})$;

for $f f=1: z$

$\mathrm{M}(\mathrm{ff}, \mathrm{ff})=\mathrm{N}(\mathrm{ff})$;

end

$\mathrm{M}(8,8)=\mathrm{m} 4+\mathrm{m} 5 ; \mathrm{M}(8,10)=\mathrm{m} 5 * 1 \mathrm{~h} ; \mathrm{M}(10,8)=\mathrm{m} 5 * 1 \mathrm{~h} ; \mathrm{M}(10,10)=\mathrm{I}+\mathrm{m} 5 * 1 \mathrm{~h} \wedge 2 ;$

$\mathrm{a} 1=\mathrm{c} 1 \mathrm{v}$;

$\mathrm{b} 1=\mathrm{c} 21+\mathrm{c} 1 \mathrm{~h}$;

$\mathrm{c} 1=\mathrm{c} 2 \mathrm{v}+\mathrm{c} 42+\mathrm{c} 32$;

$\mathrm{d} 1=\mathrm{c} 21+\mathrm{c} 2 \mathrm{~h}$;

$\mathrm{e} 1=\mathrm{c} 32+\mathrm{c} 43$;

$\mathrm{f} 1=\mathrm{C} 34$;

$\mathrm{g} 1=\mathrm{c} 42+\mathrm{c} 54+\mathrm{c} 43+\mathrm{c} 4 \mathrm{v}$

$\mathrm{h} 1=\mathrm{c} 4 \mathrm{~h}+\mathrm{c} 34+\mathrm{c} 5 \mathrm{~h}$;

$\mathrm{n} 1=\mathrm{c} 54+\mathrm{c} 5 \mathrm{v}$;

$\mathrm{p} 1=\mathrm{c} 5 \mathrm{~h} * 1 \mathrm{~h} \wedge 2+\mathrm{cr}$;

$\mathrm{a} 2=\mathrm{k} 1 \mathrm{v}$;

$\mathrm{b} 2=\mathrm{k} 21+\mathrm{k} 1 \mathrm{~h}$;

$\mathrm{c} 2=\mathrm{k} 2 \mathrm{v}+\mathrm{k} 42+\mathrm{k} 32$;

$\mathrm{d} 2=\mathrm{k} 21+\mathrm{k} 2 \mathrm{~h}$;

$\mathrm{e} 2=\mathrm{k} 32+\mathrm{k} 43$;

$\mathrm{f} 2=\mathrm{k} 34$;

$\mathrm{g} 2=\mathrm{k} 42+\mathrm{k} 54+\mathrm{k} 43+\mathrm{k} 4 \mathrm{v}$;

$\mathrm{h} 2=\mathrm{k} 4 \mathrm{~h}+\mathrm{k} 34+\mathrm{k} 5 \mathrm{~h}$;

$\mathrm{n} 2=\mathrm{k} 54+\mathrm{k} 5 \mathrm{v}$;

$\mathrm{p} 2=\mathrm{k} 5 \mathrm{~h} * 1 \mathrm{~h} \wedge 2+\mathrm{kr}$

\begin{tabular}{|c|c|c|c|c|c|c|c|c|c|c|}
\hline \multirow{10}{*}{$\mathrm{C}=$} & [a] & 0 & 0 & 0 & 0 & 0 & 0 & 0 & 0 & $0 ;$ \\
\hline & 0 & b1 & 0 & $-c 21$ & 0 & 0 & 0 & 0 & 0 & 0 \\
\hline & 0 & 0 & c1 & 0 & $-c 32$ & 0 & $-c 42$ & 0 & 0 & 0 \\
\hline & 0 & $-c 21$ & 0 & d1 & 0 & 0 & 0 & 0 & 0 & 0 \\
\hline & 0 & 0 & $-c 32$ & 0 & e1 & 0 & $-c 43$ & 0 & 0 & 0 \\
\hline & 0 & 0 & 0 & 0 & 0 & $\mathrm{f} 1$ & 0 & $-c 34$ & 0 & 0 \\
\hline & 0 & 0 & $-c 42$ & 0 & $-c 43$ & 0 & g1 & 0 & $-c 54$ & 0 \\
\hline & 0 & 0 & 0 & 0 & 0 & $-c 34$ & 0 & h1 & 0 & $-c 5 h * 1 h$ \\
\hline & 0 & 0 & 0 & 0 & 0 & 0 & $-c 54$ & 0 & $\mathrm{n} 1$ & 0 \\
\hline & 0 & 0 & 0 & 0 & 0 & 0 & 0 & $-c 5 h * 1 h$ & 0 & p1] ; \\
\hline \multirow[t]{8}{*}{$\mathrm{K}=$} & [a2 & 0 & 0 & 0 & 0 & 0 & 0 & 0 & 0 & $0 ;$ \\
\hline & 0 & $\mathrm{~b} 2$ & 0 & $-\mathrm{k} 21$ & 0 & 0 & 0 & 0 & 0 & 0 \\
\hline & 0 & 0 & c2 & 0 & $-k 32$ & 0 & $-k 42$ & 0 & 0 & 0 \\
\hline & 0 & $-\mathrm{k} 21$ & 0 & $\mathrm{~d} 2$ & 0 & 0 & 0 & 0 & 0 & 0 \\
\hline & 0 & 0 & $-\mathrm{k} 32$ & 0 & e2 & 0 & $-k 43$ & 0 & 0 & 0 \\
\hline & 0 & 0 & 0 & 0 & 0 & f2 & 0 & $-\mathrm{k} 34$ & 0 & 0 \\
\hline & 0 & 0 & $-\mathrm{k} 42$ & 0 & $-k 43$ & 0 & g2 & 0 & $-\mathrm{k} 54$ & 0 \\
\hline & 0 & 0 & 0 & 0 & 0 & $-k 34$ & 0 & h2 & 0 & $-k 5 h * 1 h$ \\
\hline
\end{tabular}




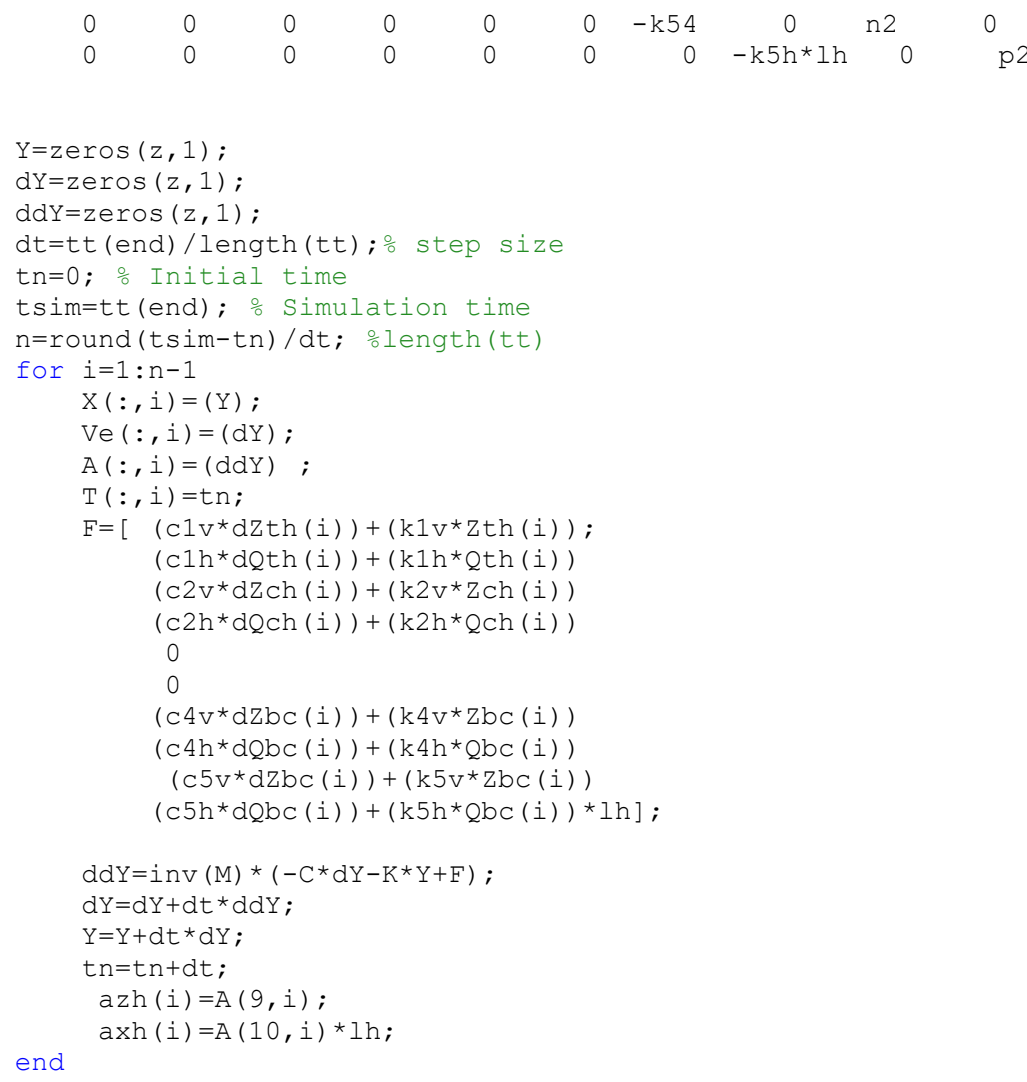

